\title{
T-Cell Lymphoblastic Lymphoma Presenting as Bilateral Multinodular Breast Masses: A Case Report and Review of the Literature
}

\author{
Efsevia Vakiani, ${ }^{1}$ David G. Savage, ${ }^{2}$ Eliza Pile-Spellman, ${ }^{3}$ Mahmoud El-Tamer, ${ }^{4}$ Ila R. Singh, ${ }^{1}$ \\ Vundavalli S. Murty, ${ }^{1}$ Bachir Alobeid, ${ }^{1}$ and Govind Bhagat ${ }^{1 *}$ \\ ${ }^{1}$ Department of Pathology, Columbia Presbyterian Medical Center, New York, New York \\ ${ }^{2}$ Department of Medicine, Columbia Presbyterian Medical Center, New York, New York \\ ${ }^{3}$ Department of Radiology, Columbia Presbyterian Medical Center, New York, New York \\ ${ }^{4}$ Department of Surgery, Columbia Presbyterian Medical Center, New York, New York
}

\begin{abstract}
Non-Hodgkin lymphoma of T-cell lineage involving the breast is rare. We report on a 41-year-old woman with T-cell lymphoblastic lymphoma who presented with multiple bilateral breast masses. The patient was treated with intensive chemotherapy and mediastinal and whole-brain irradiation. She remains in complete remission 24 months after diagnosis. The clinical, histologic, phenotypic, and cytogenetic features are described, with a review of the literature. Am. J. Hematol. 80:216-222, $2005 . \quad$ ๑ 2005 Wiley-Liss, Inc.
\end{abstract}

Key words: T-cell lymphoblastic lymphoma; breast

\section{INTRODUCTION}

Lymphoblastic lymphoma (LBL) is a high-grade lymphoma that represents $2-4 \%$ of all adult nonHodgkin lymphomas (NHLs) in Western countries $[1,2]$. Most cases are of T-cell lineage $(80-85 \%)$, and occur in adolescents and young adult males [3]. The typical presentation is of a rapidly growing mediastinal mass associated with pleural and pericardial effusions and B symptoms. Most patients present with advanced stage (III/IV) disease, and bone marrow involvement occurs in $30-50 \%$ of cases $[3,4]$. Other common sites of involvement include the peripheral lymph nodes (usually supradiaphragmatic), central nervous system (CNS), spleen, liver, and gonads $[3,4]$.

Since T-cell LBL (T-LBL) has many similarities with T-cell acute lymphoblastic leukemia (T-ALL), many investigators consider T-LBL and T-ALL different manifestations of the same disease [4]. T-ALL comprises $25 \%$ of adult ALL cases, and is more common in young males [5]. T-ALL patients typically present with involvement of the bone marrow and peripheral blood, but a mediastinal mass is often present. The distinction between T-LBL and T-ALL is arbitrary: patients with $>25 \%$ of blasts in the bone marrow are deemed to have ALL [3]. Despite simila- rities between T-ALL and T-LBL, distinct phenotypic and cytogenetic differences have been described, suggesting the presence of distinct subtypes within the two entities [3].

T-LBL is an aggressive NHL with a 5-year survival of $26 \%$ [2]. Complete remission (CR) and disease-free survival (DFS) rates have improved significantly in the past few years with the use of intensive multiagent chemotherapy, including CNS prophylaxis, similar to that used for T-ALL.

We present a case of T-LBL presenting as bilateral breast masses associated with a previously unreported balanced reciprocal translocation $\mathrm{t}(3,11)(\mathrm{q} 21$; p12-13). The clinical, histologic, phenotypic, and genetic features are presented, with a review of the literature.

*Correspondence to: Dr. Govind Bhagat, Assistant Professor of Clinical Pathology, Department of Pathology, Columbia Presbyterian Medical Center, 630 West $168^{\text {th }}$ Street, New York, NY 10033. E-mail: gb96@columbia.edu

Received for publication 20 January 2005; Accepted 26 March 2005

Published online in Wiley InterScience (www.interscience.wiley.com). DOI: 10.1002/ajh.20448 


\section{CLINICAL SUMMARY}

A 41-year-old Afro-Caribbean woman, without any significant past medical history, noted bilateral breast lumps in October 2002. She denied any associated symptoms, including fever, night sweats, and weight loss. Clinical evaluation in January 2003 revealed multiple masses in both breasts, but no axillary, cervical, or inguinal lymphadenopathy was detected. A chest radiograph and abdominal and pelvic ultrasonography were normal. Her blood counts, calcium, erythrocyte sedimentation rate (ESR), lactic dehydrogenase (LDH), and uric acid were all within normal limits. Bilateral breast biopsies were performed, and a diagnosis of "nodular, small cleaved-cell" NHL was rendered. She was referred to our hospital for further evaluation and treatment.

On presentation, she was found to have bilateral, multiple, firm, and nontender breast nodules, varying in size from 1-3 cm. Physical examination was otherwise normal, as were her blood counts, LDH, and calcium levels. A serologic test for human T-cell leukemia virus (HTLV)-I was negative. Mammography (Fig. 1a) detected six masses measuring $2.6 \mathrm{~cm}$ in greatest dimension in the left breast, and seven masses measuring $3.3 \mathrm{~cm}$ in greatest dimension in the right breast. A computed tomography (CT) scan (Fig. 1b) of the neck, chest, abdomen, and pelvis showed softtissue opacities in the superior anterior mediastinum and in the inferior posterior mediastinum, as well as an enlarged $2-\mathrm{cm}$ right internal mammary lymph node. A positron emission tomography (PET) scan (Fig. 1c) demonstrated bilateral uptake in the breast, mediastinum, and retroperitoneum. Bilateral excisional breast biopsies demonstrated multiple, dense, nodular, and diffuse infiltrates of T-lymphoblasts, but a staging marrow biopsy was negative.

The patient was considered to have stage III TLBL, for which she was treated according to the protocol of the German Multicenter Study Group for ALL (GMALL) [6], which included systemic and intrathecal chemotherapy as well as mediastinal and whole-brain radiation therapy. Treatment was complicated by an episode of disseminated herpes zoster for which she was hospitalized and received intravenous acyclovir. She also required extensive transfusion and growth-factor support. Upon completion of therapy, there was no evidence of disease on physical
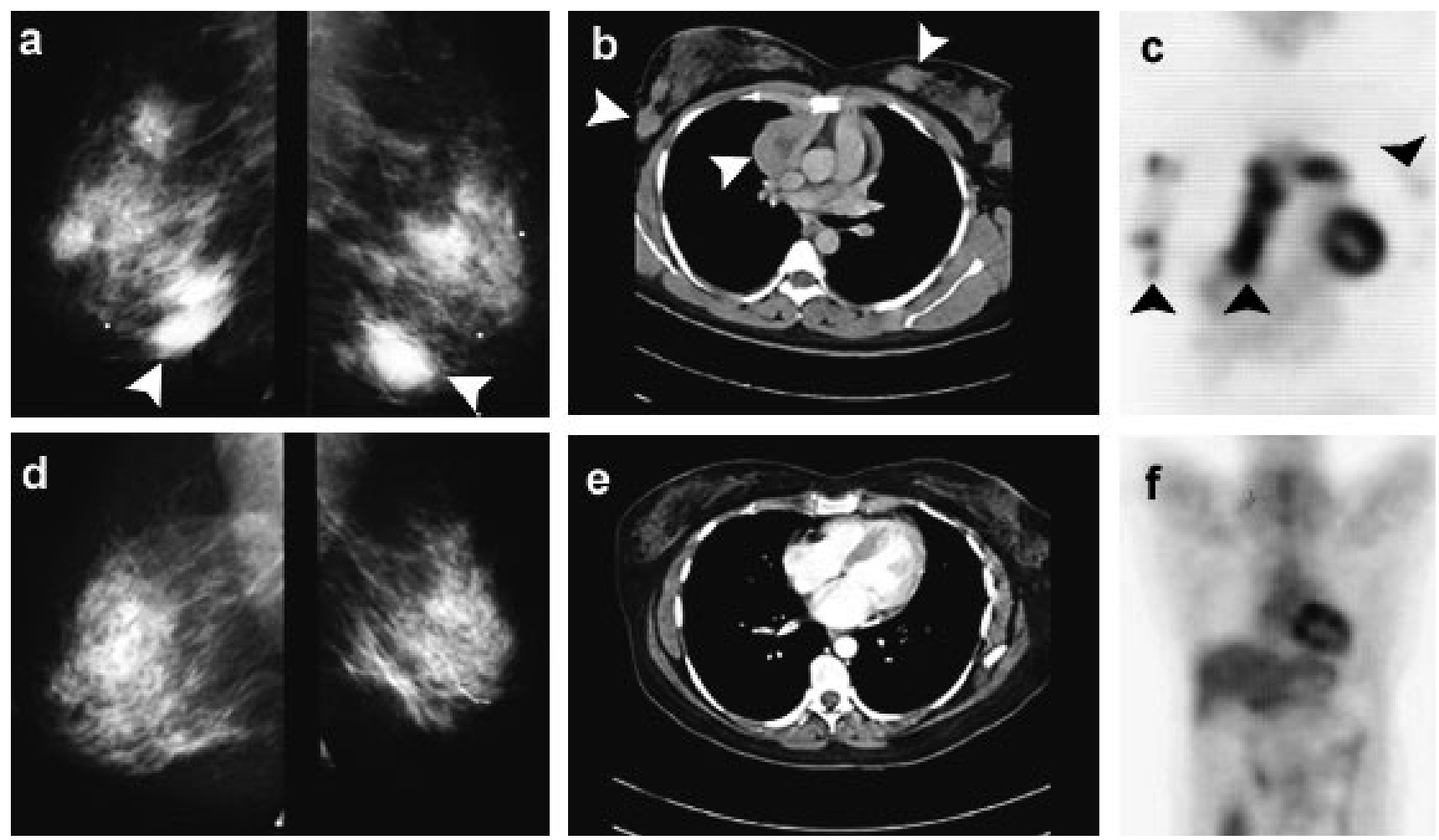

Fig. 1. Imaging studies pre- and posttreatment. a: Pretreatment mammogram shows bilateral nodular breast masses (arrowheads, large masses in inferior quadrants). b: Pretreatment CT scan demonstrates breast and mediastinal disease (arrowheads). c: Pretreatment PET scan shows increased uptake of radiotracer in breast and mediastinum (arrowheads). Posttreatment mammogram (d), CT (e), and PET scans (f) show no evidence of disease. 
examination, mammography, CT, or PET scans (Fig. 1d-f). She remains in clinical and radiographic remission 12 months after completion of treatment.

\section{MATERIALS AND METHODS}

Hematoxylin and eosin (HE) and immunohistochemical (IHC) stains were performed on $3-\mu \mathrm{m}$ formalin-fixed, paraffin-embedded tissue sections. The following antibodies were used for IHC analysis: CD3, CD8, CD20, CD79a, bcl-6, Ki-67, ALK-1, CD99 (DakoCytomation, Carpinteria, CA), CD2, CD4, CD5, CD7, CD30, CD57 (Novocastra, Burlingame, CA), CD43, bcl-2 (Biogenex, San Ramon, CA), p53, TIA-1 (Immunotech, Westbrook, ME), TdT (Supertech, Bethesda, MD), and panCK (AE1/ AE3, Boehringer Mannheim, Indianapolis, IN). The DakoCytomation Envision Plus System (DakoCytomation) was used for detection. In situ hybridization (ISH) was performed using a probe for Epstein-Barr virus (EBV)-encoded viral RNAs (EBER 1-2, Ventana, INFORM EBER, Tucson, AZ).

Three-color flow cytometric analysis (FACScan, Becton Dickinson, San Diego, CA) was performed on the breast biopsy tissue, using Cell Quest software (Becton Dickinson) according to standard procedures. T-, B-, natural killer (NK)-cell, and myeloid lineage antigens were analyzed, using a comprehensive panel of monoclonal antibodies.

Polymerase chain reaction (PCR) for the T-cell receptor (TCR)- $\gamma$ gene and immunoglobulin heavy chain $(\operatorname{IgH})$ gene rearrangements was performed on fresh tissue, as previously described $[7,8]$.

PCR to detect HTLV-I and -II was also performed on fresh tissue, using primers to amplify a 268-bp sequence of the HTLV-I and -II gag gene and a 148bp sequence of the HTLV-I tax gene (unpublished protocol). HTLV-II DNA and DNA from a known HTLV-I-associated T-cell lymphoma were used as positive controls.

G-banding was performed on metaphases obtained from overnight (12-15 hr) unstimulated cultures, using standard procedures. Twelve cells were karyotyped and reported according to the International System for Human Cytogenetic Nomenclature (ISCN) 1995 [9].

\section{RESULTS}

Excisional biopsies of the right and left breast masses showed a dense, vaguely nodular, and diffuse lymphoid infiltration of the breast parenchyma, with extension into mammary fat (Fig. 2a). The infiltrate was composed of lymphocytes showing a spectrum from small cells with round nuclei and coarse chromatin to medium and focally large-sized cells with fine
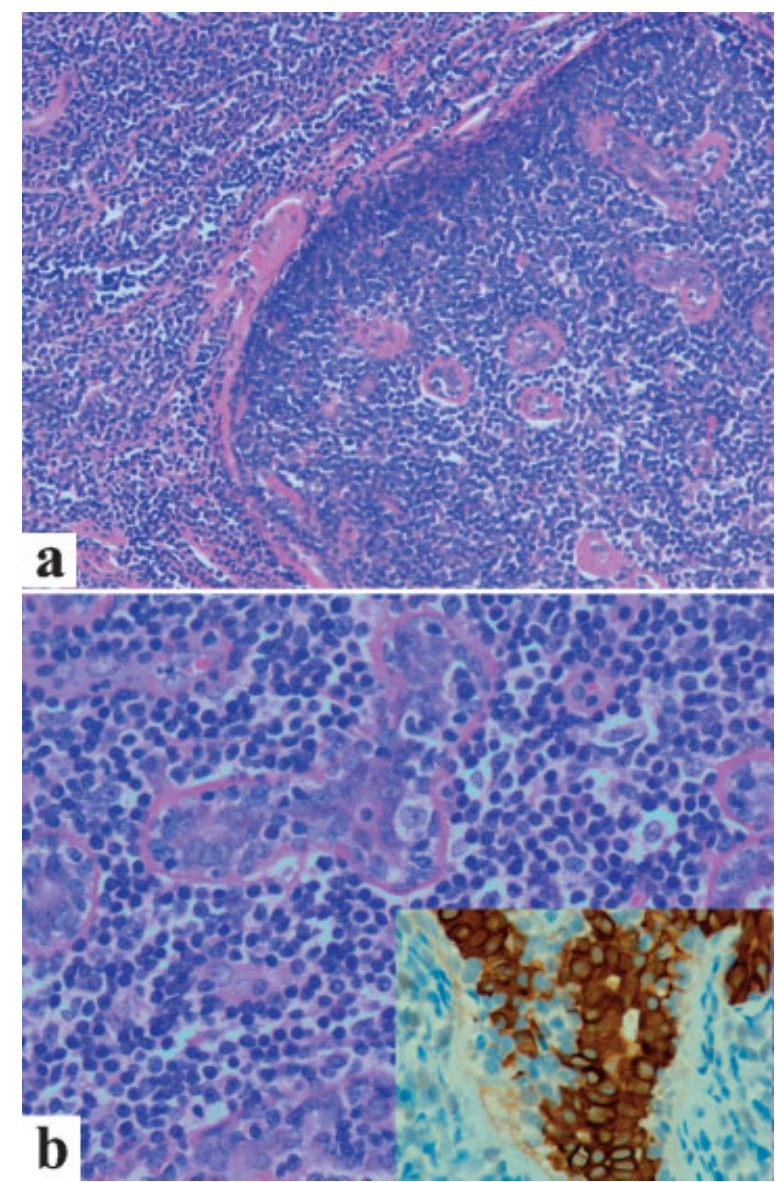

Fig. 2. Morphology of breast T-LBL. a: Mixed nodular ("Iobulocentric") and diffuse pattern of lymphoblast infiltration (HE, $\times 50)$. b: Lymphoepithelial lesion $(\mathrm{HE}, \times 200)$ highlighted by staining with pan-cytokeratin (inset, $\times 400$ ). [Color figure can be viewed in the online issue, which is available at www.interscience. wiley.com.]

stippled chromatin, indistinct nucleoli, and scant cytoplasm, consistent with lymphoblasts. Numerous mitotic figures and foci of single-cell necrosis were identified. Lymphoblasts infiltrated between the acini, expanding the lobules, in a lobulocentric pattern. Occasional foci of epithelial infiltration by the lymphoblasts, forming lymphoepithelial lesions (LELs), were highlighted with a pan-cytokeratin stain (Fig. 2b). The adjacent uninvolved breast parenchyma showed mild fibrosis and lobular sclerosis.

The lymphoblasts were TdT + (Fig. 3c), CD99+, $\mathrm{CD} 3+$ (Fig. 3a), CD7 +, and focally CD5+, but did not express CD2 (Fig. 3b), CD4, or CD8 ("double negative" (DN) T-cells). A moderate infiltrate of small reactive $\mathrm{CD} 4+\mathrm{T}$-cells was also present. The blasts expressed CD43 and bcl-2, and approximately 50\% showed faint cytoplasmic staining with CD79a (Fig. 3d) as well as weak staining for CD30. The Ki-67 labeling index was virtually $100 \%$, and nuclear p53 staining 


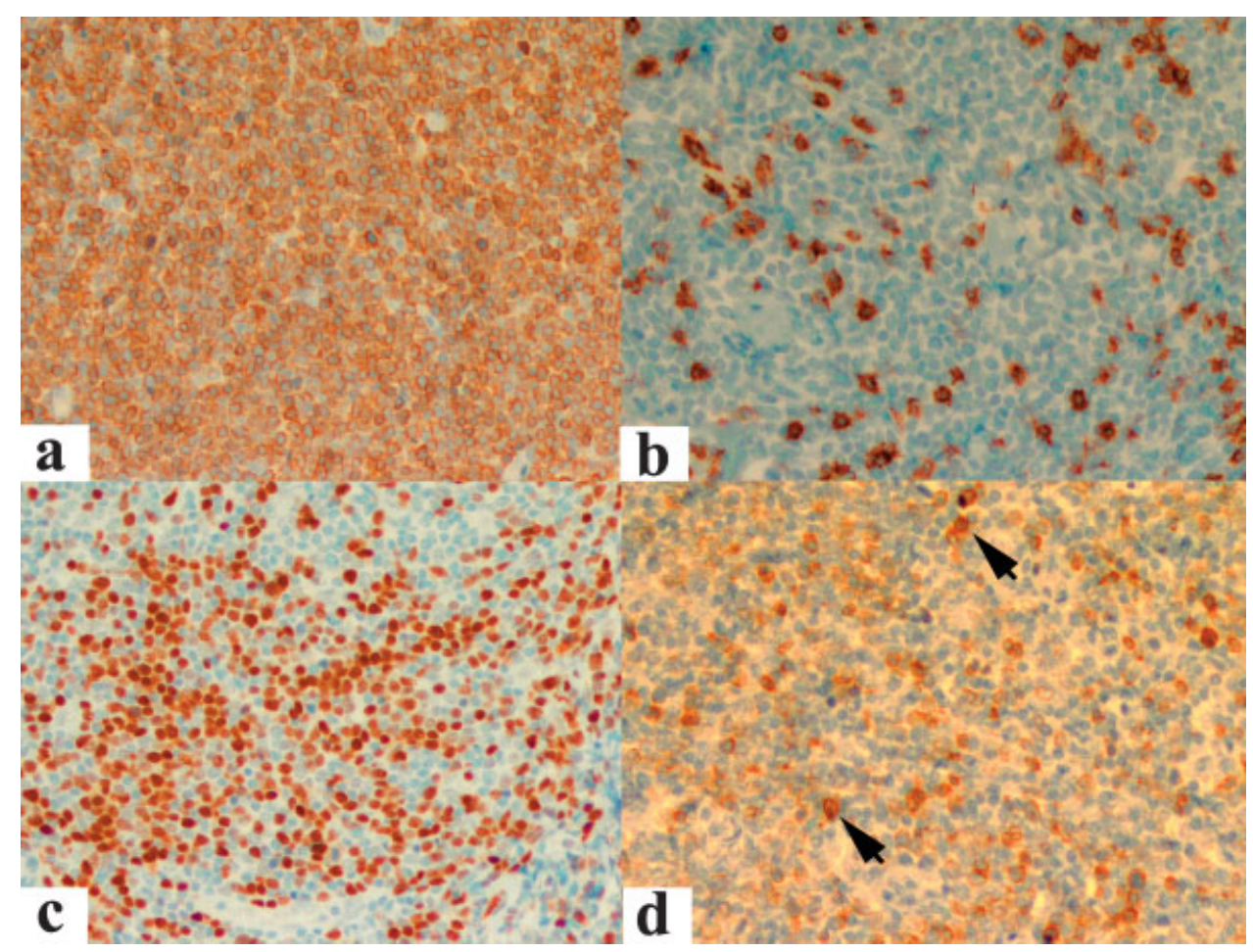

Fig. 3. IHC staining of T-LBL $(\times 200)$ a: Lymphoblasts show cytoplasmic CD3 staining. b: CD2 staining highlights reactive T-cells, but lymphoblasts are negative. c: Majority of lymphoblasts express TdT. d: Weak cytoplasmic CD79a expression in lymphoblasts; cells with intense staining (arrows) represent scattered, admixed, mature B-cells. [Color figure can be viewed in the online issue, which is available at www.interscience.wiley.com.]

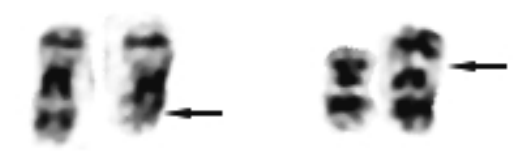

\section{chr 3 (der 3) chr 11 (der 11)}

Fig. 4. Partial G-band karyotype of T-LBL.

was seen in up to $20 \%$ of blasts. No staining was seen with CD34, CD20, bcl-6, ALK-1, TIA-1, and CD56, and in situ hybridization for EBER was negative.

Flow cytometry confirmed the presence of an immature $(\mathrm{TdT}+)$ population of medium-sized cells with dim CD45 expression, cytoplasmic (but absent surface) CD3, and variable CD117, HLA-DR, CD30, and CD79a (cytoplasmic) expression. Blasts were negative for CD34, CD1a, CD10, CD16 + 56, CD25, CD13, CD33, and myeloperoxidase (MPO). No surface expression of the $\mathrm{TCR} \alpha / \beta, \mathrm{TCR} \gamma / \delta$, or Ig heavy chains was identified.

IHC staining of the bone marrow biopsy and flow cytometric analysis of the marrow aspirate showed no evidence of disease.

PCR for TCR- $\gamma$ and IgH gene rearrangements demonstrated clonal and polyclonal products, respectively. Absence of HTLV-I and -II DNA was confirmed by PCR analysis. Karyotypic analysis of lymphoblasts showed a $\mathrm{t}(3 ; 11)(\mathrm{q} 21 ; \mathrm{p} 12-13)$ translocation in 5 of 12 cells analyzed (Fig. 4).

\section{DISCUSSION}

NHLs of the breast are uncommon, comprising between $0.04-0.5 \%$ of all malignant breast neoplasms in most series, and $1.7-2.2 \%$ of extranodal NHLs in Western countries [10]. The majority of breast NHLs are of B-cell phenotype, with the frequency of T-cell NHLs ranging from 2.5-7.5\% [11-14]. Several types of T-cell NHL have been reported in the breast, including anaplastic large-cell lymphoma, peripheral T-cell lymphoma not otherwise specified (NOS), adult T-cell lymphoma/leukemia (ATLL), and NK/ T-cell lymphoma $[15,16]$.

Involvement of the breast by T-LBL is unusual. A search of the literature yielded 9 cases (Table I), including 2 single case reports [17,18] and 7 patients included in larger series $[11-13,19,20]$. In an additional 2 cases of LBL reported in the earlier literature, no data regarding B- or T-cell lineage was provided [21]. Breast involvement by T-ALL (not included in Table I), albeit infrequent, has also been reported [22]. Furthermore, since previously published reports of T-LBL provided inadequate histologic and phenotypic characterization, 
TABLE I. Reported Cases of T-LBL Involving Breast*

\begin{tabular}{|c|c|c|c|c|c|c|}
\hline $\begin{array}{l}\text { Age } \\
\text { (years) }\end{array}$ & Stage & IHC profile & $\begin{array}{c}\text { Survival after } \\
\text { diagnosis (months) }\end{array}$ & Treatment & CNS prophylaxis & References \\
\hline 20 & $\mathrm{IV}^{\mathrm{a}}$ & $\mathrm{CD} 3+$ & 12 & CHOP & Yes & 17 \\
\hline 30 & IV & $\mathrm{CD} 3+, \mathrm{CD} 45 \mathrm{RO}+$ & 14 & $\mathrm{CHOP}+\mathrm{RT}$ & No & 20 \\
\hline 20 & IV & $\mathrm{CD} 45 \mathrm{RO}+$ & $0^{\mathrm{b}}$ & $\begin{array}{l}\text { Cytoxan, methotrexate, } \\
\text { vincristine, adriamycine }\end{array}$ & $\mathrm{N} / \mathrm{A}$ & 18 \\
\hline 17 & III & $\mathrm{CD} 45 \mathrm{RO}+, \mathrm{CD} 4+, \mathrm{CD} 8+$ & 12 & Chemo, ${ }^{\mathrm{c}} \mathrm{RT}$ & $\mathrm{N} / \mathrm{A}$ & 13 \\
\hline 41 & III & See Results & 24 & $\begin{array}{c}\text { Chemo (GMALL protocol), } \\
\text { RT (brain, mediastinum) }\end{array}$ & Yes & Present case \\
\hline
\end{tabular}

*Five additional reported cases had absent or limited phenotype, and clinical information was not provided [11,12,19].

$\mathrm{RT}$, radiotherapy; N/A, not available.

aBone marrow and peripheral blood were involved, and patient had hepatomegaly; reported as "leukemic" phase of T-LBL.

${ }^{\mathrm{b}}$ Patient died of sepsis during treatment.

${ }^{\mathrm{c}}$ Regimen not specified.

it has not been possible to distinguish between T-LBL and T-ALL in a few cases.

Based on the limited clinical information available, it appears that all the reported patients were young women (17-30 years old) who had a dismal outcome, all of the patients dying of disease a maximum of 14 months after diagnosis (Table I). Only one patient [17] treated with CHOP, intrathecal methotrexate, and cranial radiotherapy followed by maintenance therapy with 6-mercaptopurine and methotrexate achieved complete remission. However, this patient relapsed after 4 months and died 12 months after diagnosis.

There is considerable emphasis in the literature on the distinction between primary and secondary NHLs of the breast. Although some authors define primary breast NHLs as those that present in the breast [18], most authors reserve that term for lymphomas when there is no evidence of disease outside the breast. The published cases of T-LBL, where information was provided $[13,17,18,20]$, all appeared to be secondary, since there was evidence of disease outside the breast at time of presentation. In our patient, there was evidence of mediastinal disease as well as retroperitoneal adenopathy on staging workup. Thus, although the true site of origin cannot be assigned unequivocally, lymphatic dissemination to the breast from a mediastinal primary is likely.

Our patient presented with multiple breast masses. NHLs of the breast typically present as a unilateral mass; the frequency of bilateral disease at presentation ranges from 5-25\% [10]. Among previous reports of T-LBL in which adequate clinical detail was provided, 2 of 5 patients presented with bilateral masses [12,20]. One patient [12] was a 22-year-old woman who presented with bilateral breast lymphoma postpartum, similar to reports of Burkitt lymphomas of the breast in women of childbearing age. The latter is thought to be due to expression of pro- lactin receptors by the lymphoma cells [23]. Prolactin receptors are also expressed on DN thymocytes [24], but the exact role of these receptors in lymphoblasttrafficking to the breast is not known.

The histology of previously reported T-LBL cases is not described in any significant detail. Yumuk et al. [17] described diffuse infiltration of the breast by lymphoblasts in their case of T-LBL in leukemic phase. In our patient, there was a predominantly nodular (lobulocentric) pattern (Fig. 2a), and LELs were also present (Fig. 2b). The latter have been reported for other types of breast lymphomas [1113], including one case of T-LBL [11].

The lymphoblasts of our patient were CD34-, $\mathrm{TdT}+, \mathrm{CD} 2-, \mathrm{CD} 3(\mathrm{cyt})+, \mathrm{CD} 5($ partial $)+, \mathrm{CD} 7+$, CD4-, CD8-, CD25-, surface TCR $\alpha / \beta$ and TCR $\gamma /$ $\delta-$, and demonstrated a clonal rearrangement of the $\mathrm{TCR} \gamma$ gene. This profile suggests that the neoplasm originated from an early thymic T-cell precursor population, resembling the DN2/pro-T2 stage of normal thymocyte development [25], most likely in the mediastinum, with subsequent spread to the breasts.

Expression of CD117 but absent Bcl-6 expression is also consistent with an early $\mathrm{T}$-cell precursor origin of the blasts. Bcl- 6 expression is less often observed in TLBL with a DN phenotype [26], while CD117 is known to play a role in early thymocyte (DN stage) development [27]. CD117 expression was reported in up to $40 \%$ of patients with T-ALL/LBL [28], and is more commonly seen in cases with the most immature phenotypes [29]. Expression of CD13, a non-Trestricted marker, is often observed in CD117+ TLBLs [29], probably reflecting a prethymic precursor phenotype. The lack of CD13 and CD34 expression in our case is consistent with the phenotype of $\mathrm{T}$ lineage-committed thymic lymphoblasts [30].

The lymphoblasts in our case expressed CD79a and CD99. Up to $52 \%$ of T-LBLs express CD79a [31], a 
subunit of the B-cell antigen receptor complex, originally thought to be a specific marker of normal and neoplastic B cells. Moreover, CD79a expression appears to be restricted to DN T-LBLs [31] and is of lower intensity compared to B cells, as also observed in our case (Fig. 3d). CD99 is expressed in $80-90 \%$ of T-LBLs [32], and appears to correlate with TdT expression [33]. In the thymus, CD99 is expressed at high levels not only in very early $\mathrm{T}$-lineage cells but also in CD4 + CD8 + or double-positive (DP) thymocytes [34]. The function of this protein at the early DN stage of development is not known, but a role in the mediation of apoptosis of maturing (DP) thymocytes was demonstrated [35].

Expression of CD30 by neoplastic lymphoblasts, albeit at a weak level, is unusual. CD30 expression in T-LBLs was reported to be negative [3], though one study found expression of a variant CD30 isoform in 3 of 14 T-ALL cases [36]. In the normal thymus, CD30 is expressed in the medulla and is thought to play a role in negative selection [37]. Among T-cell lymphomas, CD30 expression is characteristic of anaplastic large-cell lymphoma, but was also described in several cases of ATLL, where it was linked to HTLV provirus integration [38]. We ruled out the possibility of an association with HTLV in our case, since a serologic test as well as PCR for HTLV DNA were both negative.

Chromosomal abnormalities in T-LBL are similar to those described for T-ALL. Commonly occurring translocations juxtapose the regulatory regions of TCR genes, located at chromosomes 14q11, 7q32-36, and $7 \mathrm{p} 15$, with proto-oncogenes, usually transcription factors, that include Tal1, Tal2, Lyl1, Lom2, and Lck [4]. Intriguingly, some of these transcription factors are expressed in early (DN) thymocytes [39], and the oncogenic fusion transcripts are thought to cause dysregulated growth and maturation arrest of the lymphoblasts. Other chromosomal translocations, not involving the TCR genes, were also reported in TLBL $[40,41]$. Cytogenetic analysis of our case showed a $\mathrm{t}(3 ; 11)(\mathrm{q} 21 ; \mathrm{p} 12-13)$ translocation (Fig. 4), which was not previously reported in T-LBL. Since the resolution of the G-band karyotype was not optimal, the breakpoint on chromosome $11 \mathrm{p}$ could not be determined with accuracy. It is notable, however, that one of the oncogenes implicated in T-ALL/LBL pathogenesis, Lom2, is located at chromosome 11p13.

Treatment of T-LBL with CHOP-like regimens has not been very effective, with $\mathrm{CR}$ rates between 50 $71 \%$ and DFS rates between $23-53 \%$ at 5 years [4]. Intensive chemotherapy regimens, including CNS prophylaxis, similar to those used for T-ALL, resulted in improved CR rates (77-95\%) and DFS rates of $45-67 \%$ at 5 years $[4,6]$. Mediastinal recur- rence has been one of the most common causes of failure, resulting in the adoption of mediastinal irradiation in more recent protocols [42]. The GMALL protocol includes mediastinal irradiation, and was associated with a $93 \% \mathrm{CR}$ rate and $62 \%$ DFS at 7 years [6]. In the GMALL report, the probability of survival was higher in patients with stage I/II disease ( $83 \%$ survival at 4 years) compared to those with stage III/IV disease (48\% survival at 4 years) [6]. Previous studies found that high LDH, stage IV disease, marrow involvement, B symptoms, CNS involvement, and age older than 40 years is associated with a worse prognosis [4]. Our patient had stage III disease with a normal LDH level, no B symptoms, and no CNS or bone marrow involvement.

In conclusion, we report on a highly unusual case of T-LBL presenting as bilateral, multinodular, lobulocentric breast masses that was successfully treated with intensive chemotherapy, CNS prophylaxis, and mediastinal irradiation. Our report represents the first detailed immunohistochemical, flow cytometric, cytogenetic, and molecular analysis of a T-LBL presenting in the breast.

\section{REFERENCES}

1. Armitage JO, Weisenburger DD. New approach to classifying non-Hodgkin's lymphomas: clinical features of the major histologic subtypes. Non-Hodgkin's Lymphoma Classification Project. J Clin Oncol 1998;16:2780-2795.

2. Non-Hodgkin's Lymphoma Pathologic Classification Project. National Cancer Institute sponsored study of classifications of non-Hodgkin's lymphomas: summary and description of a working formulation for clinical usage. Cancer 1982;49:2112-2135.

3. Knowles DM. Lymphoblastic lymphoma. In: Knowles DM, editor. Neoplastic hematopathology. Baltimore: Williams \& Wilkins; 1992. p. 715-747.

4. Thomas DA, Kantarjian HM. Lymphoblastic lymphoma. Hematol Oncol Clin North Am 2001;15:51-95.

5. Borowitz M. Acute lymphoblastic leukemia. In: Knowles DM, editor. Neoplastic hematopathology. Baltimore: Williams \& Wilkins; 1992. p. 1295-1314.

6. Hoelzer D, Gokbuget N, Digel W, Faak T, Kneba M, Reutzel R, Romejko-Jarosinska J, Zwolinski J, Walewski J. Outcome of adult patients with T-lymphoblastic lymphoma treated according to protocols for acute lymphoblastic leukemia. Blood 2002;99:4379-4385.

7. Sioutos N, Bagg A, Michaud GY, Irving SG, Hartmann DP, Siragy H, Oliveri DR, Locker J, Cossman J. Polymerase chain reaction versus Southern blot hybridization. Detection of immunoglobulin heavy-chain gene rearrangements. Diagn Mol Pathol 1995;4:8-13.

8. Bottaro M, Berti E, Biondi A, Migone N, Crosti L. Heteroduplex analysis of T-cell receptor gamma gene rearrangements for diagnosis and monitoring of cutaneous T-cell lymphomas. Blood 1994;83:3271-3278.

9. Mitelman F, editor. An international system for human cytogenetic nomenclature (1995): recommendations of the International Standing Committee on Human Cytogenetic Nomenclature, Memphis, TN, USA, October 9-13, 1994. Basel: S. Karger; 1995. 
10. Brogi E, Harris NL. Lymphomas of the breast: pathology and clinical behavior. Semin Oncol 1999;26:357-364.

11. Cohen PL, Brooks JJ. Lymphomas of the breast. A clinicopathologic and immunohistochemical study of primary and secondary cases. Cancer 1991;67:1359-1369.

12. Arber DA, Simpson JF, Weiss LM, Rappaport H. Non-Hodgkin's lymphoma involving the breast. Am J Surg Pathol 1994; 18:288-295.

13. Hugh JC, Jackson FI, Hanson J, Poppema S. Primary breast lymphoma. An immunohistologic study of 20 new cases. Cancer 1990;66:2602-2611.

14. Vianello F, Sgarabotto D, Stefani PM, Radossi P, Sartori R, Sartori D, Girolami A. Primary breast lymphoma. Forum (Genova) 1998:8:188-195.

15. Kosaka M, Tsuchihashi N, Takishita M, Miyamoto Y, Okagawa K, Gotoh T, Saito S, Komaki M, Morimoto T, Sano T. Primary adult T-cell lymphoma of the breast. Acta Haematol (Basel) 1992;87:202-205.

16. Aguilera NS, Tavassoli FA, Chu WS, Abbondanzo SL. T-cell lymphoma presenting in the breast: a histologic, immunophenotypic and molecular genetic study of four cases. Mod Pathol 2000;13:599-605.

17. Yumuk PF, Aydiner A, Topuz E, Cabioglu N, Dogan O. T-cell lymphoblastic lymphoma presenting with a breast mass. Leuk Lymphoma 2004;45:833-836.

18. Sung DW, Lim JW, Yoon Y, Kim YW, Lee JH, Cho KS. Primary breast lymphoma. J Korean Med Sci 1993;8:210-213.

19. Morel P, Lepage E, Brice P, Dupriez B, D'Agay MF, Fenaux P, Gosselin B, Bauters F, Gisselbrecht C. Prognosis and treatment of lymphoblastic lymphoma in adults: a report on 80 patients. J Clin Oncol 1992;10:1078-1085.

20. Au WY, Chan AC, Chow LW, Liang R. Lymphoma of the breast in Hong Kong Chinese. Hematol Oncol 1997;15:33-38.

21. Carbone A, Volpe R, Tirelli U, Veronesi A, Galligioni E, Trovo MG, Grigoletto E. Primary lymphoblastic lymphoma of the breast. Clin Oncol 1982;8:367-373.

22. Ellegaard J, Bendix-Hansen K, Boesen AM, Thorling K, Hokland P. Breast tumour as a first manifestation of extramedullary relapse in acute lymphoblastic leukaemia. Scand J Haematol 1984;33:288-294.

23. Diebold J, Jaffe E, Raphael M, Warnke R. Burkitt lymphoma. In: Jaffe E, Harris N, Stein H, Vardiman J, editors. Pathology and genetics: tumours of haematopoietic and lymphoid tissues. Lyon: IARC Press; 2001. p 181-184.

24. Dardenne M, de Moraes MC, Kelly PA, Gagnerault MC. Prolactin receptor expression in human hematopoietic tissues analyzed by flow cytofluorometry. Endocrinology 1994;134:2108-2114.

25. Ceredig R, Rolink T. A positive look at double-negative thymocytes. Nat Rev Immunol 2002;2:888-897.

26. Hyjek E, Chadburn A, Liu YF, Cesarman E, Knowles DM. BCL6 protein is expressed in precursor T-cell lymphoblastic lymphoma and in prenatal and postnatal thymus. Blood 2001;97:270-276.

27. Broudy VC. Stem cell factor and hematopoiesis. Blood 1997; 90:1345-1364.

28. Tomeczkowski J, Frick D, Schwinzer B, Wittner N, Ludwig WD, Reiter A, Welte K, Sykora KW. Expression and regulation of c-kit receptor and response to stem cell factor in childhood malignant T-lymphoblastic cells. Leukemia 1998;12:1221-1229.
29. Nishii K, Kita K, Miwa H, Kawakami K, Nakase K, Masuya M, Morita N, Omay SB, Otsuji N, Fukumoto M, et al. c-kit gene expression in CD7-positive acute lymphoblastic leukemia: close correlation with expression of myeloid-associated antigen CD13. Leukemia 1992;6:662-668.

30. Asnafi V, Beldjord K, Boulanger E, Comba B, Le Tutour P, Estienne MH, Davi F, Landman-Parker J, Quartier P, Buzyn A, Delabesse E, Valensi F, Macintyre E. Analysis of TCR, pT alpha, and RAG-1 in T-acute lymphoblastic leukemias improves understanding of early human T-lymphoid lineage commitment. Blood 2003;101: 2693-2703.

31. Hashimoto M, Yamashita Y, Mori N. Immunohistochemical detection of CD79a expression in precursor $\mathrm{T}$ cell lymphoblastic lymphoma/leukaemias. J Pathol 2002;197:341-347.

32. Riopel M, Dickman PS, Link MP, Perlman EJ. MIC2 analysis in pediatric lymphomas and leukemias. Hum Pathol 1994;25: 396-399.

33. Robertson PB, Neiman RS, Worapongpaiboon S, John K, Orazi A. 013 (CD99) positivity in hematologic proliferations correlates with TdT positivity. Mod Pathol 1997;10:277-282.

34. Dworzak MN, Fritsch G, Buchinger P, Fleischer C, Printz D, Zellner A, Schollhammer A, Steiner G, Ambros PF, Gadner H. Flow cytometric assessment of human MIC2 expression in bone marrow, thymus, and peripheral blood. Blood 1994;83:415-425.

35. Bernard G, Breittmayer JP, de Matteis M, Trampont P, Hofman P, Senik A, Bernard A. Apoptosis of immature thymocytes mediated by E2/CD99. J Immunol 1997;158:2543-2550.

36. Horie R, Gattei V, Ito K, Imajo-Ohmi S, Tange T, Miyauchi J, Pinto A, Degan M, De Iuliis A, Tassan Mazzocco F, Rossi FM, Higashihara M, Watanabe T. Frequent expression of the variant CD30 in human malignant myeloid and lymphoid neoplasms. Am J Pathol 1999;155: 2029-2041.

37. Chiarle R, Podda A, Prolla G, Gong J, Thorbecke GJ, Inghirami G. CD30 in normal and neoplastic cells. Clin Immunol 1999;90: 157-164.

38. Ohtsuka E, Kikuchi H, Nasu M, Takita-Sonoda Y, Fujii H, Yokoyama S. Clinicopathological features of adult T-cell leukemia with CD30 antigen expression. Leuk Lymphoma 1994;15: 303-310.

39. Tabrizifard S, Olaru A, Plotkin J, Fallahi-Sichani M, Livak F, Petrie HT. Analysis of transcription factor expression during discrete stages of postnatal thymocyte differentiation. J Immunol 2004;173:1094-1102.

40. Kaneko Y, Frizzera G, Maseki N, Sakurai M, Komada Y, Hiyoshi Y, Nakadate H, Takeda T. A novel translocation, $\mathrm{t}(9 ; 17)(\mathrm{q} 34 ; \mathrm{q} 23)$, in aggressive childhood lymphoblastic lymphoma. Leukemia 1988;2: 745-748.

41. Bohlander SK, Muschinsky V, Schrader K, Siebert R, Schlegelberger B, Harder L, Schemmel V, Fonatsch C, Ludwig WD, Hiddemann W, Dreyling MH. Molecular analysis of the CALM/ AF10 fusion: identical rearrangements in acute myeloid leukemia, acute lymphoblastic leukemia and malignant lymphoma patients. Leukemia 2000;14:93-99.

42. Dabaja BS, Ha CS, Thomas DA, Wilder RB, Gopal R, Cortes J, Bueso-Ramos C, Hess MA, Cox JD, Kantarjian HM. The role of local radiation therapy for mediastinal disease in adults with $\mathrm{T}$-cell lymphoblastic lymphoma. Cancer 2002;94: 2738-2744. 